\title{
Laboratory Test Time
}

National Cancer Institute

\section{Source}

National Cancer Institute. Laboratory Test Time. NCI Thesaurus. Code C83152.

The time that the laboratory test was carried out. 